\title{
ALVEOLAR BONE REGENERATION AFTER DEMINERALIZED FREEZE DRIED BONE ALLOGRAFT (DFDBA) BONE GRAFTING
}

\author{
Sri Oktawati \\ Departmen of Periodontology Faculty of Dentistry Hasanuddin University
}

\begin{abstract}
Alveolar Bone Regeneration After Demineralized Freeze Dried Bone Allograft (DFBDA) Bone Grafting

Periodontal treatment by conventional way will result in healing repair, which easily cause recurrence. Modification of treatment should be done to get an effective result, that is the regeneration of alveolar bone and to reduce inflammation. The objective of this study is to determine the alveolar bone regeneration after using DFDBA (Demineralized Freeze Dried Allograft). Quasi experimental designs with pre and post test method was used in this study. From 13 patients, 26 defects got conventional or regenerative treatment. The indicator of alveolar bone regeneration in bone height in radiographic appearence and level of osteocalsin in gingival crevicular fluid (GCF) were checked before and after the treatment, then the changes that occure were analyzed. The result of the research showed that alveolar bone regeneration only occurred to the group of regenerative treatment by using DFDBA. The conclusion is the effective periodontal tissue regeneration occurred at regenerative treatment by using DFDBA, and the osteocalsin in GCF can be used as indicator of bone growth. Indonesian Journal of Dentistry 2006; Edisi Khusus KPPIKG XIV:37-4I
\end{abstract}

Key words : alveolar bone regeneration, osteocalsin

\section{Introduction}

Periodontal disease is generally initiated by gingival inflammation followed by other supporting tissue breakdown, including alveolar bone. With debridement only or conventional treatment, the destruction can not be restored. Substraction radiography study showed that bone density after root planing was $5 \%$ only. ${ }^{2}$ Yukna ${ }^{3}$ showed that SRP (Scaling Root Planing) treatment in periodontitis could only produce pocket covering, but histological and radiological findings revealed minimal alveolar bone regeneration. These problems might cause the prevalence of periodontal disease was still high. Therefore, the effort to modify the treatment was required, for example regenerative treatment.
Regeneration ini periodontal disease, will result bears of new bone at place of lesion occurred, ${ }^{4}$ have so long that evaluation of successful regenerative treatment is base on clinical, radiology and histology evaluation. This assessment have some weakness, thus we try to evaluate the regenerations by bone graft with Demineralized Freeze Dried Allograft (DFDBA) using osteoclastin in Gingival Crevicular Fluid (GCF) as an indicator. The effication of this study is to measure exactly the gain of treatment, and further be the basic of treatment planning.

\section{Alveolar Bone Resorption}

Bone resorption process is initiated by the extension of gingival infiammation through transeptal fiber, then it extends to bone marrow, replaced by exudates fluid, new blood vessets, and 
replaced by exudates fluid, new blood vessels, and fibroblast proliferation. Multinuclear osteoclast increases in number and bone surface bordered with resorption gap is in wedge form. This osteoclast function to produce bone mineral and mononuclear cell functions by destructing organic matrix.'

\section{Alveolar Bone Regeneration}

Regeneration is defined as the reproduction of destructive or injure part. This biological process consist of the improvement of architecture and tissue function. Periodontal regeneration process includes alveolar bone restoration, periodontal ligament, and cementum. Histologically, the definition of regeneration is connective tissue or epithelial unification with root surface obtained from attachment organ. This new attachment can be epithelial adhesion or connective tissue adaptation. ${ }^{4}$ Regenerative treatment is periodontal disease treatment designed to gain the replacement of lost supporting tissue, including alveolar bone and new periodontal ligament. $^{5}$

Growth factor is polypeptide molecule excreted by cells in inflammatory sites and will organize bone healing. This factor can organize locally functional hormones and it does not enter the blood flow. Growth substance arranges the migration and proliferation of supporting tissue cells, protein syntheses, and other component of extracellular matrix. ${ }^{1}$ These factors are secreted by macrophage, endothelial cell, fibroblast, and platelets. These factors, include platelet-derived growth factors (PDGF), insulin-like growth factor (IGF), fibroblastic growth factor (FGF), and transforming growth factor (TGF). The factors trigger fibroblast proliferation of periodontal ligament and bone forming. ${ }^{6}$ There is no special contraindication for this treatment, except general contraindication for periodontal surgery, such as acute or systemic condition causing risk for patients.

Cellular events involving bone forming and surface remodeling include ${ }^{4.7}$ :

- Osteoclast activity cessation and the absence of multinucleate osteoclast in resorption site. This mechanism was carried out by calcium and phosphate ion that is free from transforming growth factor $\beta$ (TGF- $\beta$ ) role which is the osteoclast activity inhibitor and strong osteoclast apoptosis cause.

- Attraction of osteoblast precursor in that site. There are several mechanism in osteoblast precursor chemo attraction. Chemo tactic signal can involve bone matrix part, such as osteocalcin, TGF- $\beta$, Platelet-Derived Growth Factor (PDGF).

- Osteoblast precursor proliferation. Several strong bone cell mitogen, those are insulin-like growth factor-1 (ILGF-1), ILGF-2, PDGF, and TGF- $\beta$.

- Precursor change form mature collagen: produce osteoblast. In vitro, BMP plays a role in this process.

- Mineralization of bone matrix, BMP also plays a role in this process.

- Cessation of osteoblast activity

\section{Bone Graft}

Bone graft is a surgery to place a new bone in the space between or around the broken bone or defect. It is known that there are 4 groups of agent or graft source; autograft, allograft, xenograft, and alloplast. The main function of all bone graft agent

- Osteoconduction; graft acts as pattern or net to guide bone formation.

- Osteoinduction; graft works to stimulate new bone formation.

- Osteogenesis; graft cell produces new bone.

Allograft has osteoinductive capacity. Bone tissue must be obtained under controlled condition from selective donor, to ensure that tissue is acceptive histopathologically, and could be transmitted. The advantage of allograft compared with autograft is that it doesn't need adjunctive surgery to get donor by keeping the balanced improvement potency. More donor is available, more indications could be done. ${ }^{3,8}$

Some bone graft agents were aimed to improve bone defect. The agent DFDBA is the most common agent. This allograft could control disease transmission, variability, supply and application method. The other agent, like alloplast, is not possible to transmit the disease and donor is not limited, but it doesn't have bone inductor protein. $9.10,11$ The steps of this DFDBA are selective criteria and strict donor processing, bone was taken surgically, freeze dried, make until the particle size is $300-500$ mees $/ \mu$, and put in vacuum-sealed bottle with unlimited storage time.

\section{Material and Method}

This study was a clinical experiment, that is a quasi experimental with non randomized pre and post test control group design. Strong theoretical base of immunopathology supported variable 
Jynamic and complex process. These are many factors involved in human body change. That's why the selection of measurement tools is required specifically. To avoid systemic effect of change, GCF was used as fluid closed to observed site.

This study is involve 13 patient with 26 bone defect. Patient is chosen according inclusion and exclusion criteria, and than classified with flap operation group and flap operation plus DFDBA group. Three month later the patient reevaluation. Aveolar bone regenerative indicators were Jetemined by radiographic finding, bone height aldition base on radio-opaque on bone defect, and the increase of osteoblast biological activity by observing one of its secretion, osteocalcin. The increase of GCF osteocalcin level is the marker of the increase of osteoblast number, that means the increase of bone forming activity.

\section{Result}

Examination before and after treatment in treatment group revealed the significant difference in bone height and osteocalcin. Control group also showed a significant difference in bone height, but there is no significant difference in osteocalcin with paired t-test ( $\mathrm{P} \leq 0,05)$, as shown in Table 1 .

The examination between treatment and control grolsp before treatment for bone height and osteocalcin didn't show significant difference. Significant difference in bone height and osteocalcin was found with independent t-test $(P \leq 0,05)$, as shown in Table 2.

Bone height before treatment in two groups differed, in treatment group, bone height mean was 4 $\mathrm{mm}$, in control group, $3 \mathrm{~mm}$. After treatment, in treatment group, bone height mean decreased to 2 $\mathrm{mm}$, that means the bone position increased. Whereas, in control group, bone height man didn't change as seen at Diagram 1.

Osteocalcin level was shown in Diagram 2. Before treatment, the level was the same $0,5 \mathrm{mg} / \mathrm{ml}$. After treatment, osteocalcin level was increased in treatment group $2 \mathrm{mg} / \mathrm{ml}$, in control group, the increase is lower, $1,3 \mathrm{mg} / \mathrm{ml}$.

Tablel. The Difference Pre and Post Test in Treatment and Control Group for Bone Height and Osteocalcin.

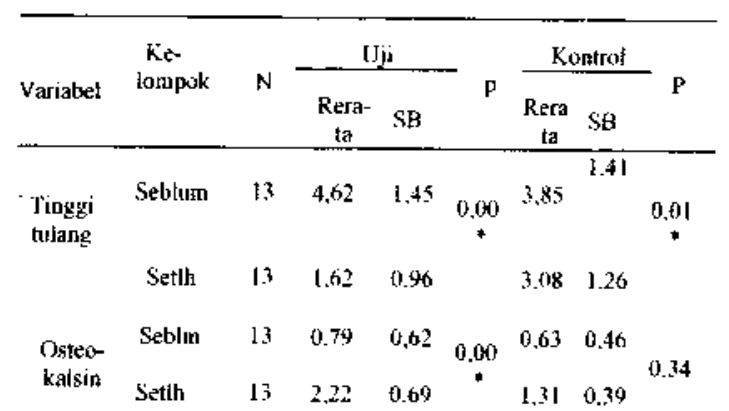

Table 2. The Difference in Treatment and Control Group Pre and Post Test for Bone Height and Osteocalcin.

\begin{tabular}{|c|c|c|c|c|c|c|c|}
\hline \multirow{2}{*}{ Vaziabel } & \multirow{2}{*}{$\begin{array}{c}\text { Kelom- } \\
\text { posk }\end{array}$} & \multicolumn{3}{|c|}{ Sebeltant } & \multicolumn{3}{|c|}{ Setelah } \\
\hline & & $\mathrm{N}$ & rerata & $P$ & $\mathrm{~N}$ & retala & $\boldsymbol{P}$ \\
\hline \multirow{2}{*}{$\begin{array}{l}\text { Tingyit } \\
\text { Anlanỵ }\end{array}$} & viji & 13 & 4,62 & ij & 13 & $\$ .62$ & \multirow{2}{*}{$0.00^{*}$} \\
\hline & kontrol & 13 & 3.85 & 18 & 13 & 3.108 & \\
\hline \multirow{2}{*}{$\begin{array}{l}\text { Osteo } \\
\text { kalsin }\end{array}$} & Uji & 13 & 0.79 & 0. & 13 & 2.22 & \multirow{2}{*}{$0.00^{*}$} \\
\hline & kontrol & 13 & 0.66 & 55 & 1.3 & I.31 & \\
\hline
\end{tabular}

Diagram 1. The Distribution of Bone Height Radiological Figure Before and After Treament

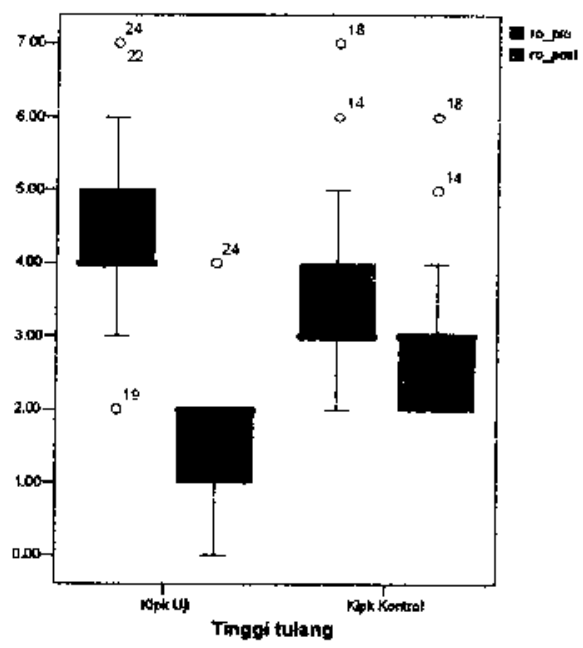

Diagram 2. The Distribution of Osteocalcin Level Before and After 'Treatment 


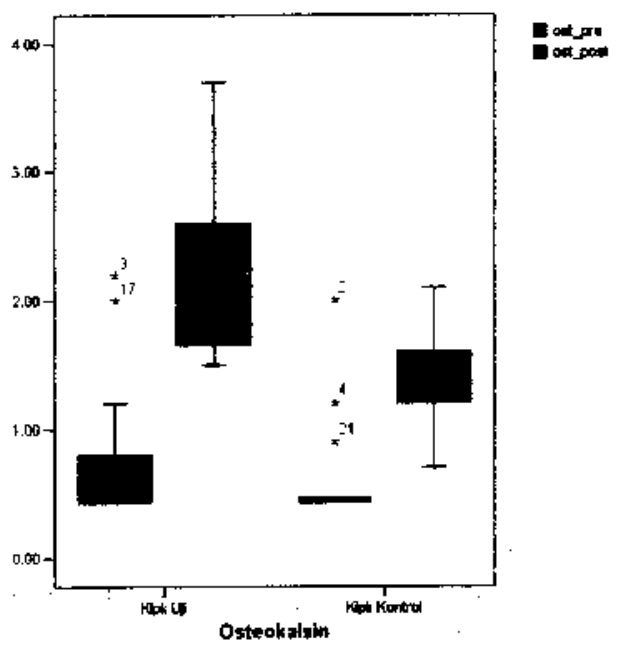

\section{Discussion}

Regenerative effort by DFDBA agent addition in this study was occurred by modifying healing process through osteoinduction, with the availability of growth factor. Osteoinduction runs mechanically as bone growth site and prevented epithelial growth in injurious direction. One of the growth factors contained in DFDBA matrix bone is BMP working as regulator of development and repair of cells, including osteoblast, chondroblast, nerve cell, and epithelium. Demineralized Freeze Dried Bone Allograft is also multifunctional morphogen which regulating development and apoptosis ${ }^{12}$ and it is proved to initiate cementum and periodontal ligament regeneration.

In this study, there was bone mass increase after treatment both in treatment group and control group. But the increase is higher in treatment group or in the group with regenerative treatment by DFDBA. This result was obtained from the difference between two groups. Bone filling based on the radiography showed mean $3 \mathrm{~mm}$ and this result is equal to Crurinsky. ${ }^{13}$ But, this value is higher than of Hudoyono ${ }^{14}$, around $1,32 \mathrm{~mm}$. This different result was caused by inaccuracy of radiography or the difference in method and measurement tools used.

Bone regeneration resulted from allograft was varied. This was caused by bone inductive protein was not enough to produce bone, inactive bone inductive component, and the difference of sterilization process in host. The agent used in this study had been sterilized by radiation, while radiation can decrease the capability of bone induction until $40 \%$, that's why allograft with other sterilization will give significant result.

Regenerative treatment using other agent, for example membrane, showed bone filling effect. Study of Lindhe ${ }^{8}$ showed that bone filling is $1.7 \mathrm{~mm}$ and Mattson ${ }^{14}$ showed $2,15 \mathrm{~mm}$, and this study showed that bone filling is $3 \mathrm{~mm}$. The results of these three studies described the superiority of DFDBA. This is caused by DFDBA function as osteoinduction and osteoconduction, while membrane just limits epithelial development and allows cells to differentiate and proliferate without modifying its precursor cells. This difference could be happened because of the difference in the examination method.

DFDBA agent used in this study was included in small particles group $(100-300$ mees $/ \mu)$. This is possible to give the success of alveolar bone regeneration, for small particles will increase the surface area and osteogentic induction. With light microscope and fluorescence, Shapoff ${ }^{45}$ revealed that small particles would increased bone marrow necroses and released osteogenic agent and stimulated host celt around graft area becoming osteoblast. Smaller particles $(<100$ mees $/ \mu$ ) will be resorbed without bone formation.

The examination of osteocalcin level in GCF was carried out to clear the occurrence of alveolar bone regeneration in this study. Osteocalcin level examination is believed as the marker of bone growth activity ${ }^{16,17,18}$. Osteccalcin value in GCF obtained by researcher is very varied. Kunimatsu ${ }^{19}$ reported high value, $200-500$ times that in serum. In this study, the examination of level in serum was not carried out, so that we could not compare to Kunimatsu ${ }^{19}$, and the value was different. This is caused by the difference in measurement tools sensitivity, so that the values were different entirely.

There was an increase in osteocalcin value in regenerative treatment group, but not in conventional treatment group. This result was supported by vahue difference after treatment between two groups. This finding proved that in molecular level, bone growth was maximal in regenerative treatment group compared with conventional treatment group. Researcher got mean value $0,79 \mathrm{ng} / \mathrm{dL}$ before treatment and $2,22 \mathrm{ng} / \mathrm{dL}$ after treatment in regenerative treatment group, while median $0,66 \mathrm{ng} / \mathrm{dL}$ before treatment and 1,31 $\mathrm{ng} / \mathrm{dL}$ after treatment for conservative treatment group (Table 4). This value increased significantly in two groups. This finding could explain that bone 
ny/dL after treatment for conservative treatment group (Table 4). This value increased significantly in two groups. This finding could explain that bone irowth process was occurred by osteoblast in two freatment groups. Osteocalcin value increase was higher in regenerative treatment group. This showed that DFDBA played a role in regeneration process

Sensitivity limit of measure instrument used in the study is $0,35 \mathrm{ng} / \mathrm{dL}, 70 \%$ of samples (18 of 26) examined. Before treatment showed the value under this sensitivity limit, but after treatment, osteocalcin value could be detected in all samples with varied value. This findings revealed that undetectable osteocalcin caused osteoblast as bone growth precursor didn't work maximally before treatment. This was probably caused by high level inflammation and many other etiological factors. The result of the study suggested that osteocalcin examination significance can be used as a marker of bone growth process after regenerative treatment with DFDBA.

\section{Conclusion and Suggestion}

1. Alveolar bone regeneration was occurred both in regenerative and conventional treatment.

2. Alveolar bone regeneration was better in regenerative treatment than conventional treatment.

3. Osteocalcin examination in GCF could be used as bone growth marker in regenerative treatment with DFDBA.

\section{References}

1. Carranza FA, Bulkacz. Detense Mechanisms of the Gingival. Carranza's Clinical Periodontology: $9^{\text {th }}$ ed. Philadelphia: WB Saunders Co 2002: 254-9.

2. Brock DL. Bone regeneration after root planing. <www.google.com.> Diakses 19 Maret 2003.

3. Yukna RA. Management of Oseus Defects. Bone Replacement Girafts: The Periodontic Syllabus $3^{\text {rd }}$ ed. Baltimore: Lea and Febiger, 1995

4 American Academy of Periodontology (AAP). Periodontal Regencration. Research, Science and Therapy Comitec. 2003

5. Grossi SG, Genco RJ, Matchtei FE. Assessment of Risk for Periodontal disease. II. Risk indicators for alveolar bone loss. J Periodontol. 1995; 66: 23-9.

6. Giannobile WV. Lynch SE. Denmark RG, Paquette DW. Fiorellini JP, Williams RC, Crevicular Fluid Osteocalsin and Pyridinoline Cross-linked Carboxyterminal Telopeptide of Type l Collagen (ICTP) As Marker of Rapid Bone Turnover in
Periodontitis. A pilot Study in Beagie Dogs. $J$ Chin Periodontol 1995; 22: 903-10.

7. Mundy GR, Boyce B, Hughes D. The Eiffects of Cytokines and (irowth Factors on Osteoblastic Cells. Binc 1045: 17: 71s-5s.

8. Mellonig JT, Schwartz \%, Boyan BD. Position P'aper. Tissue Banking of Bone Allografts Lised in Periodontal Regeneration. J Periodontol 2001; 72 : 834-8.

9. Mellonig JT. I'rewett AB. Moyer MP. HIIV Inactivation in $A$ Bone Allograft. I Periodontol 1992: 63: 979-83.

10. Russo R. Scalborough N. Inactivation of Viruses in Demineralized Bone Matrix. Bcthesda: FDA Workshop on Tissue Transplantation and Reproductive Tissue. 1995: 10-21.

11. Hall EE, Meffert RM. Hermann S. Comparison of Bioactive Glass to Demineralized Freezc-dried Bone Allograft in the Treatment of intrabony Defects around Implants in the Canine Mandible. $J$ Periodontol 1999; 70: 526-35.

12. Ripamonti IJ. Tasker JR. Advances in Bjotcchnology for Tissue Engineering of Bone. International Conference Bone Morphogenetic Proteins 2000. <www google com > Diakses tanggal 23 Mei 2003.

13. Gurinsky BS, Mills MP. Mellonig JT. Clinical Evaluation of Demineralized Freeze Dried Bone Allograft and Enamel Matrix Derivative versus Enamel Matrix Derivative Alone for the Treatment of Periodontal Osseous Defects in Humans. Periodontol 2003; 75: 1309- 18.

14. Mattson JS, Gallagher SI, Jabro MH. The Use of 2 Bioabsorsable Barrier Membranes in the Treatment of Interproximal inntrabony Periodontal Defects. I Periodontol $1999 ; 70: 510-7$.

15. Shapoff CA. Bowers GM, Levy B. Melionig JT, Yukna RA. The fiffect of Particle Size on the Osteogenic Activily of Composite Gratts of Aliogenic Frecze-dried Bone and Autogenus Marrow. J Periodontol 1980:51: 625-30.

16. Kawashima K. Invue T. Tsutsumi N, Endo H. Effect of KCA-098 on the Function of Osteoblast-like Cells and the Formation of TRAP Positive Muitinucleated Cells in A Mouse Bone Marrow Cell Population. Biochem Pharmacol $1995: 51: 133-9$.

17. Golub 1M, Lee HM, Greenwald RA. Ryan ME. Sorsa T, Salo T. A Matrix Metalloproteinase Inhibitor Reduces Bone-type Collagen Degradation Fragments and Specific Collagenases in Gingival Crevicular Flujd during Adult Periodontitis. Inflamm Res 1997: 46:310-9.

18. Giannobile WV. Shammari KF. Sarment DP. Matrix Molecules and Growth Factor $A$ s Indicator of Periodontal Disease Activity. Periodoniol 2000 2003 :31: 125-34.

19. Kunimatsu K. Mataki S, Tanaka H. Mine N. Kiyoki M. Hosoda K, et al. A Cross Scctional Study on Osteocalsin Levels in Gingival Crevicular Fluid from Periodont Patients. J Periodontol 1993 ; 64: 865-9 